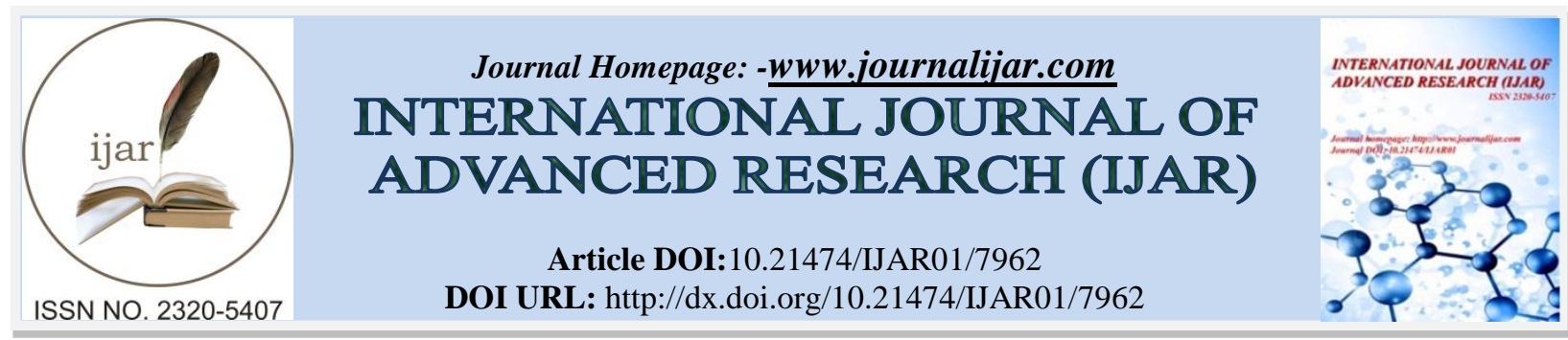

RESEARCH ARTICLE

\title{
DIVERSIFICATION DIAGNOSTICS FOR PORTFOLIO INVESTMENT USING COMBINATION OF CRYPTOCURRENCY AND STOCK PRICE.
}

Nashirah Abu Bakar ${ }^{1}$ and Sofian Rosbi ${ }^{2}$.

1. Islamic Business School, College Of Business, Universiti Utara Malaysia,Kedah, Malaysia.

2. School of Mechatronic Engineering, Universiti Malaysia Perlis, Malaysia.

\section{Manuscript Info}

Manuscript History

Received: 17 August 2018

Final Accepted: 19 September 2018

Published: October 2018

Keywords:-

Investment, Modern Portfolio Theory,

Diversification, Cryptocurrency,

Bitcoin.

\section{Abstract}

Main objective of this study is to develop investment portfolio with diversifications using two different assets. Modern portfolio theory develop investment portfolio to maximize expected return based on a given level of market risk. This study selected cryptocurreny (Bitcoin) and stock price (Petronas Gas Berhad) as the combination in developing investment portfolio. In this analysis, mean return for Bitcoin is $9.890 \%$. Meanwhile, the mean return for stock price of Petronas Gas Berhad is $-0.496 \%$.The value of correlation is between two assets is -0.372 . Result shows the portfolio risk can be reduced with the diversification approach for different assets. Therefore, findings of this study are important for assisting investors to maximize their return for given level of investment risk.

Copy Right, IJAR, 2018,. All rights reserved.

\section{Introduction:-}

Strategy in portfolio investment represents a core facet of investment strategy used by investors to explore investment opportunities. Research has documented forecasting methods that could help investors to choosea good investment strategic in order to maximize the return at a significant level of risk. In addition, research that use forecasting methods which are simple moving average and exponential smoothing found the exponential smoothing is less error than simple moving average (Abu Bakar and Rosbi, 2016).

Another research of forecasting methods have argued that modern portfolio theory open up opportunities to maximize portfolio expected return for a given amount of risk (Fabozzi et al., 2002; Ho, et al., 2010; Azizan and Sorooshian, 2014; Abu Bakar and Rosbi, 2018). Besides these methods, Basilio et al. (2018) developed a simulation-based approach in order to evaluate the investment portfolio selection. Even there are many research conducted the variety of method used in evaluate the performance ofshares price, but study that focus on the difference types of companies is still lack of researches. Therefore, this study try to develop a research regarding portfolio investment with combination of two differences company namely Petronas Gas Berhad and cryptocurreny (Bitcoin).

Oil and gas sector can be considered as the cornerstone of modern society, considering its role in providing affordable energy to energize production processes, fuel the global economy, provide income to producers and support everyday life (Eldomiaty et al., 2016). However, in the current economic condition oil and gas sector faced with the big challenge in generating a good return. As mention by Abu Bakar and Rosbi (2018) revenue from crude 
oil accounted of RM248 billion in 2015 compared to RM329 billion in 2014, prolonged lower oil for Petroliam Nasional Berhad (PETRONAS).

Therefore, this study choosed Petronas Gas Malaysia shares price in order to investigate the performance of this sector. The second share price selected in this study is Bitcoin cryptocurrency. Cryptocurrency is defined as a digital currency in which encryption techniques are used to regulate the generation of units of currency and verify the transfer of funds, operating independently of a central bank (Moore and Christin, 2013; Kristoufek, 2013; Decker and Wattenhofer, 2013; Simser, 2015; Reynolds and Irwin, 2017; Abu Bakar et al., 2017). Abu Bakar and Rosbi (2017) investigate the Bitcoin exchange rate found the value for 1 Bitcoin is USD 13282.29 in early December 2017. This value shows the high increment compare with other shares prices. Thus, this study developed investment portfolio with combination of two different shares price namely cryptocurreny (Bitcoin) and (Petronas Gas Berhad) using the modern portfolio theory.

\section{Literature review:-}

Since Modern Portfolio Theory (MPT) was introduced in year 1952 (Markowitz, 1952), many researchers have attempted to model the benefits of establishing diversification strategies for portfolio investments. Several lines of evidence suggest that modern portfolio theory considerable and contain many important studies of its suitability and application to establish an optimal allocation of property portfolios (Mohd. Ali, 2006; Friedman, 1971; Draper and Findlay, 1982).There is many evidence suggested the benefit of modern portfolio theory in diversification of portfolio investment. Ou (2005) carried out a research on the modern portfolio theory and risk based on incremental entropy found the new theory emphasizes that there is an objectively optimal portfolio for given probability of returns. While, Giannotti, et al. (2011) examined the benefits of modern portfolio theory found that the standard geographic and sector diversification allow for a good results and more efficient portfolios.

More recent attention has focused on the innovation of the technology especially on the digital money (also known as cryptocurrency) (Abu Bakar and Rosbi, 2017). The most famous cryptocurrency is Bitcoin. Bitcoin was developed in 2008 by developer known as Satoshi Nakamoto (Nakamoto, 2009). Then the second cryptocurrency came into market in 2014, when Vitalik Buterin and his core team developed a second generation cryptocurrency called Ethereum (Bajpai, 2018). Besides the attention on the digital currency, oil and gas industry also attracts most study to examine the performance of oil and gas share price performance. Oil and gas industry faces challenges of intensifying demands for delivery of both shareholder value and increased output to meet global demand for hydrocarbons, while at the same time ameliorating its environmental and social impact (Garcia et al., 2014). Thus, this study tries to develop the combination portfolio investment between Bitcoin cryptocurrency and Petronas Gas Berhad stock in order to provide a good combination of investment portfolio.

\section{Research Methodology:-}

The main objective of this study is to evaluate the diversification of investment portfolio using modern portfolio theory. Therefore, this study implemented data selection process, return rate calculation, normality checking, correlation diagnostics and portfolio risk calculation.

\section{Data selection process for Bitcoin and stock}

This study combines two assets from different segments. The selected two assets is cryptocurrency (Bitcoin) and stock price (Petronas Gas Berhad). Data selected from January 2017 until September 2018 (21 monthly observations). Bitcoin data is collected daily from https://www.coindesk.com. Meanwhile, the stock price of Petronas Gas Berhad is collected daily from Thomson Reuters Datastream.

\section{Return rate calculation for Bitcoin and stock}

This section described the process of calculation for return rate. The calculation of return rate is described as Equation (1).

$$
R_{i}=\left(\ln \frac{P_{i}}{P_{i-1}}\right) \times 100 \%
$$

In Equation (1), $R_{i}$ is return rate for period $i, P_{i}$ is price at period $i$, and $P_{i-1}$ is price at period $i-1$. 


\section{Shapiro-Wilk Normality checking}

The null-hypothesis of Shapiro-Wilk normality test is that the population is normally distributed. Therefore, if the pvalue is less than the chosen alpha level (0.05), then the null hypothesis is rejected and there is evidence that the data tested are not normally distributed. On the other hand, if the p-value is greater than the chosen alpha level (0.05), then the null hypothesis that the data follows a normally distributed population cannot be rejected.

The Shapiro-Wilk test tests the null hypothesis that a sample $x_{1}, x_{2}, x_{3}, \ldots, x_{n}$ came from a normally distributed population. The test statistic is described in below Equation (2).

$$
W=\frac{\left(\sum_{i=1}^{n} a_{i} x_{(i)}\right)^{2}}{\sum_{i=1}^{n}\left(x_{i}-\bar{x}\right)^{2}} .
$$

In Equation (2), the parameters are described as follows:

$x_{(i)}$ is order statistics, represents $x_{(1)}$ is smallest value in the sample,

$\bar{x}=\frac{x_{1}, x_{2}, x_{3}, \ldots, x_{n}}{n}$ is sample mean, with $n$ is number of data in the sample,

The constant $a_{i}$ are described in Equation (3).

$$
\left(a_{1}, a_{2}, a_{3}, \ldots, a_{n}\right)=\frac{m^{\mathrm{T}} V^{-1}}{\sqrt{m^{\mathrm{T}} V^{-1} V^{-1} m}}
$$

In Equation (3), the parameters are described as follows:

$$
m=\left(m_{1}, m_{2}, m_{3}, \ldots, m_{n}\right)^{\mathrm{T}}
$$

The parameters in Equation (4) aredescribed as follows:

$m_{1}, m_{2}, m_{3}, \ldots, m_{n}$ are the expected values of the order statistics of independent and identically distributed random variables sampled from the standard normal distribution,

$V$ is covariance matrix of those order statistics.

If the test statistic $\mathrm{W}$ is smaller than the critical threshold (0.05) the assumption of a normal distribution has to be rejected.

In this study, number of data for return rate is 20 observations. Therefore, the $\mathrm{W}$-value should larger than 0.905 to accept the data distribution is follow normal distribution.

\section{Pearson product moment correlation diagnostics}

Pearson product moment correlation is a measure of the linear correlation between two variables $\mathrm{X}$ and $\mathrm{Y}$. Pearson correlation coefficient is defined as the covariance of the two variables divided by the product of their standard deviations. Equation (5) indicated the detailed component for Pearson correlation coefficient.

$$
\rho_{X, Y}=\frac{\operatorname{cov}(X, Y)}{\sigma_{X} \sigma_{Y}}
$$

In Equation (5), the parameter is described as below:

$\operatorname{cov}(X, Y)$ is covariance between bivariate of variables $X$ and $Y$,

$\sigma_{X}$ is standard deviation of $X$ variable,

$\sigma_{Y}$ is standard deviation of $Y$ variable. 
Pearson's correlation coefficient when applied to a sample is commonly represented by the letter $r$ and may be referred to as the sample correlation coefficient or the sample Pearson correlation coefficient. We can obtain a formula for $r$ by substituting estimates of the covariance and variances based on a sample into the Equation (5). Consider, paired data $\mathrm{X}, \mathrm{Y}$ variables which $\left[\left(x_{1}, y_{1}\right),\left(x_{2}, y_{2}\right),\left(x_{3}, y_{3}\right), \ldots,\left(x_{n}, y_{n}\right)\right]$ are consisting of $\mathrm{n}$ pairs. Then, Equation (5) can re-arrange for sample distribution as stated in Equation (6).

$$
r=\frac{\sum_{i=1}^{n}\left[\left(x_{i}-\bar{x}\right)\left(y_{i}-\bar{y}\right)\right]}{\sqrt{\sum_{i=1}^{n}\left(x_{i}-\bar{x}\right)^{2}} \sqrt{\sum_{i=1}^{n}\left(y_{i}-\bar{y}\right)^{2}}}
$$

In Equation (6), the parameter is described as below.

$n$ is sample size, $x_{i}$ is variable $x$ at period $i$, and $y_{i}$ is variable $y$ at period $i$,

$$
\bar{x}=\frac{\sum_{i=1}^{n} x_{i}}{n} \text { is the sample mean for } x \text { variable, and } \bar{y}=\frac{\sum_{i=1}^{n} y_{i}}{n} \text { is the sample mean for } y \text { variable. }
$$

\section{Markowitz theory of diversification investment portfolio}

Modern portfolio theory (MPT), or mean-variance analysis, is a mathematical framework for assembling a portfolio of assets such that the expected return is maximized for a given level of risk.Modern Portfolio Theory makes use of the risk curve to display the potential benefits of different portfolios across the efficient frontier. Portfolios that lie below the curve or efficient frontier are sub-optimal. This indicates the combination portfolio do not provide enough return for the level of risk calculated.

The overview of Modern Portfolio Theory (MPT) is consisting of two characteristics:

1. Portfolio return is the proportion-weighted combination of the constituent assets returns.

2. Portfolio volatility is a function of the correlations of the component assets for all asset pairs

The expected return for portfolio investment of two-assets is described in Equation (7). Consider this equation is for portfolio investment of $\mathrm{X}$ and $\mathrm{Y}$ assets.

$\mathrm{E}\left(R_{P}\right)=w_{X} \mathrm{E}\left(R_{X}\right)+w_{Y} \mathrm{E}\left(R_{Y}\right)$

In Equation (7), the parameters are described as below:

$\mathrm{E}\left(R_{P}\right)$ is expected return of portfolio consist of assets $X$ and asset $Y, \mathrm{E}\left(R_{X}\right)$ is expected return of asset $X$,

$w_{X}$ is the proportion of asset $X$ in portfolio, $\mathrm{E}\left(R_{Y}\right)$ is expected return of asset $Y$, and $w_{Y}$ is the proportion of asset $Y$ in portfolio.

Next, the standard deviation of the portfolio or portfolio risk c can be expressed using Equation (8).

$$
\sigma_{p}^{2}=w_{X}^{2} \sigma_{X}^{2}+w_{Y}^{2} \sigma_{Y}^{2}+2 w_{X} w_{Y} \sigma_{X} \sigma_{Y} \rho_{X Y}
$$

In the Equation (8), the parameters are described as follows:

$\sigma_{p}^{2}$ is portfolio variance, $\sigma_{X}$ is standard deviation for asset $X, \sigma_{Y}$ is standard deviation for asset $Y$, and $\rho_{X Y}$ is Pearson correlation between asset $X$ and asset $Y$.

In general, the expected return and portfolio standard deviation can be re-arranged to a general equation. Expected return for combination of $i$ number of asset in portfolio is described in Equation (9). 
$\mathrm{E}\left(R_{P}\right)=\sum_{i=1}^{n} w_{i} \mathrm{E}\left(R_{i}\right)$

Where $R_{P}$ is the return on the portfolio, $\mathrm{E}\left(R_{i}\right)$ is the return on asset $i$ and $w_{i}$ is the weighting of component asset $i$. Portfolio variance for combination of $i$ number of asset in portfolio is described in Equation (10).

$$
\sigma_{P}^{2}=\sum_{i=1}^{n} w_{i}^{2} \sigma_{i}^{2}+\sum_{i=1}^{n} \sum_{j \neq i}^{n} w_{i} w_{j} \sigma_{i} \sigma_{j} \rho_{i j}
$$

where $\sigma$ is the standard deviation of the periodic returns on an asset, and $\rho_{i j}$ is the correlation coefficient between the returns on assets $i$ and $j$.

\section{Result and discussions:-}

This section describes result from data selection, return rate calculation, statistical normality testing and correlation analysis. The last part of analysis is indicates the finding of diversification of investment portfolio using modern portfolio theory to reduce investment risk.

\section{Bitcoin data analysis}

This study selected Bitcoin price from January 2017 until September 2018. The daily price collected fromhttps://www.coindesk.com. Figure 1 shows the dynamic behavior of Bitcoin price. The maximum value for one unit of Bitcoin price is USD 15065.28 on December 2017 ( $12^{\text {th }}$ month observation period). The minimum value for one unit of Bitcoin price is USD 911.26 on January 2017 (first month observation period).

Figure 2 shows the return rate of Bitcoin price. The highest return rate for Bitcoin is $66.20 \%$ on December 2017 $\left(12^{\text {th }}\right.$ month observation period). Meanwhile, the minimum value of return rate for Bitcoin is $-31.98 \%$ on February 2018 ( $14^{\text {th }}$ month observation period).

Next, this study evaluated the normal distribution of return rate for Bitcoin price. Firstly, graphical approach is implemented to evaluate the normality of data distribution. Figure 3 shows normality Q-Q plot for Bitcoin return. Figure 3 shows all the distributions of Bitcoin return are distributed near to reference line (red line). Therefore, the distribution of Bitcoin return follows normal distribution model.

After that, this study validated the graphical findings using numerical statistical analysis. In this study, Shapiro-Wilk normality test is selected because degree of freedom for Bitcoin return data is 20. Table 1 shows Shapiro-Wilk normality test for Bitcoin return. The significant value is 0.477 larger than 0.05 . Therefore, the distribution of data follows normal distribution.

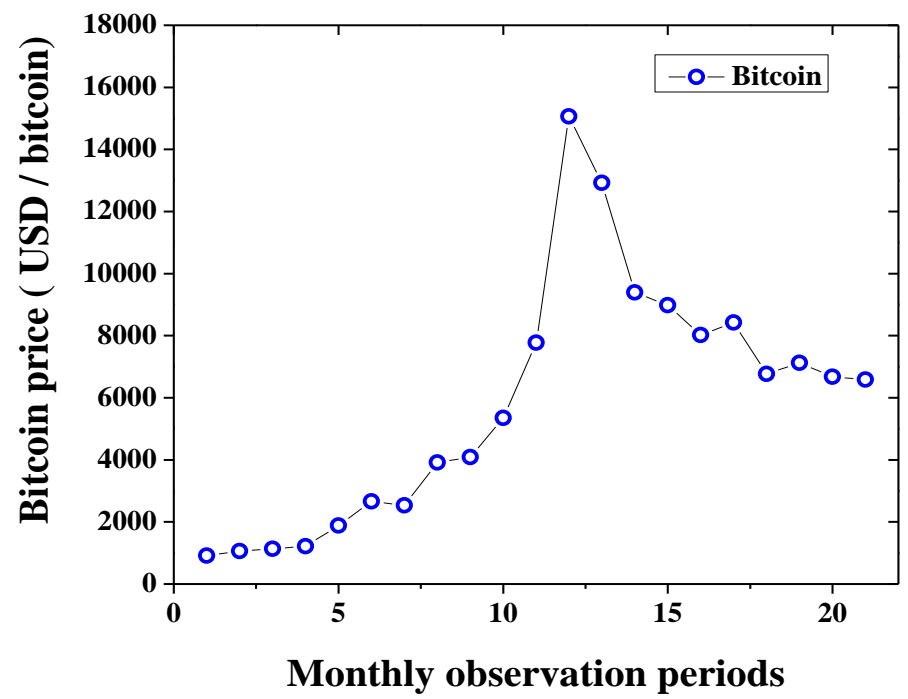

Figure 1:-Dynamic behavior of Bitcoin price 


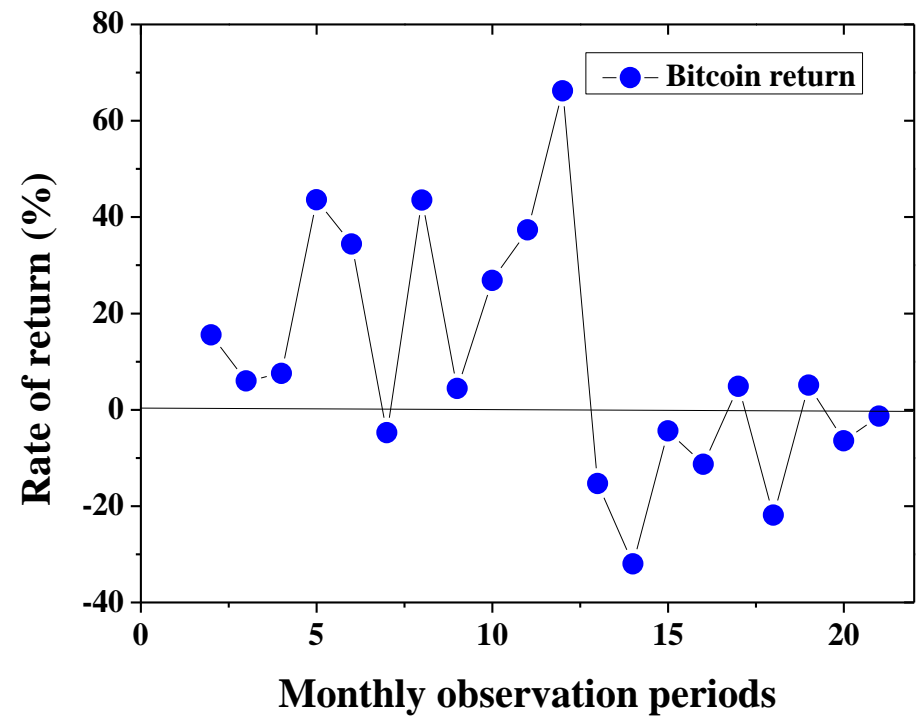

Figure 2:-Return rate for Bitcoin price

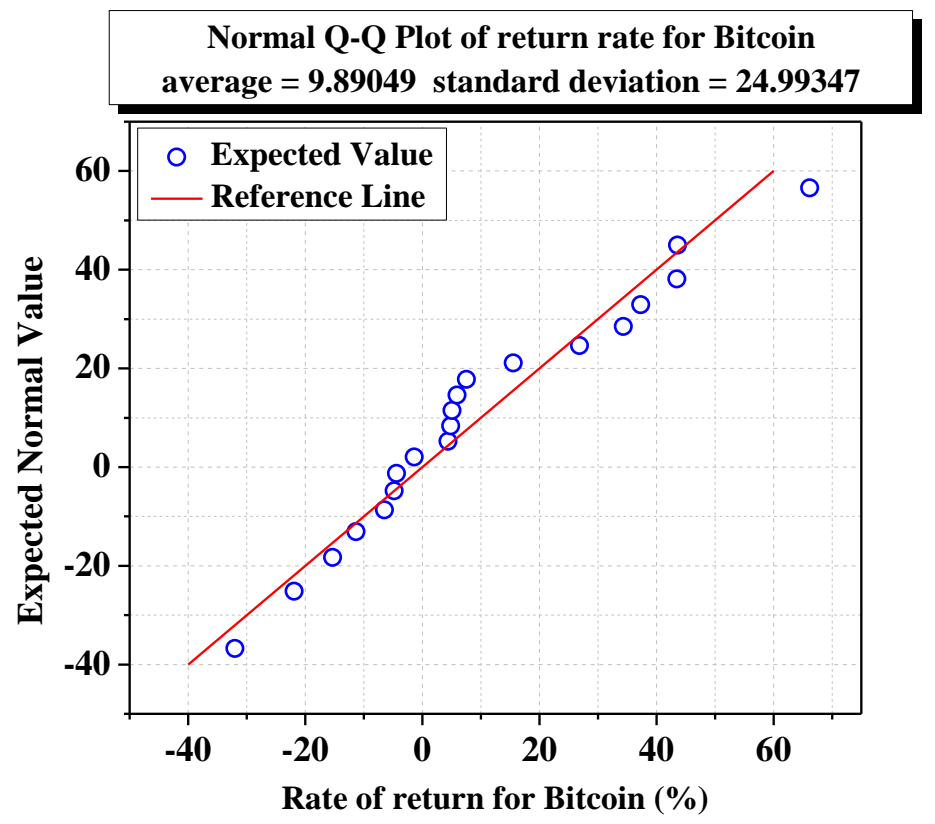

Figure 3:-Normal Q-Q normal plot of Return rate for Bitcoin price

Table 1:-Shapiro-Wilk normality test for Bitcoin

\begin{tabular}{|c|c|c|c|}
\hline Test & \multicolumn{3}{|c|}{ Shapiro-Wilk normality test } \\
\hline Parameter & Statistics & Degrees of freedom (df) & Significant value \\
\hline Return Rate for Bitcoin price & 0.957 & 20 & 0.477 \\
\hline
\end{tabular}

\section{Petronas Gas Berhad: Stock data analysis}

The second asset that selected for diversification analysis of modern portfolio theory is stock of Petronas Gas Behad. This study selected shre price from January 2017 until September 2018. The daily price collected from Thomsom Reuters Datastream. Figure 4 shows the dynamic behavior of stock price for Petronas Gas Berhad. The maximum value for one unit of stock price is MYR20.77 on January 2017 (first month observation period). The minimum value for one unit of stock price is MYR 16.49 on December 2017 ( $12^{\text {th }}$ month observation period). 
Figure 5 shows the return rate of stock price for Petronas Gas Berhad. The highest return rate for stock price is $9.96 \%$ on January 2018 ( $13^{\text {th }}$ month observation period). Meanwhile, the minimum value of return rate for stock price is $-6.77 \%$ on November 2017 ( $11^{\text {th }}$ month observation period $)$.

Next, this study evaluated the normal distribution of return rate for stock price. Firstly, graphical approach is implemented to evaluate the normality of data distribution. Figure 6 shows normality Q-Q plot for stock price return. Figure 6 shows there is one data that is deviate from to reference line (red line). This data is identified as an outlier (9.96\% return on January 2018 , the $13^{\text {th }}$ month observation period). Therefore, the distribution for return rate of stock price return is deviate from normal distribution model.

After that, this study validated the graphical findings using numerical statistical analysis. In this study Shapiro-Wilk normality test is selected because degree of freedom for stock price return data is 20 . Table 2 shows Shapiro-Wilk normality test for return rate of stock price. The significant value is 0.030 less than 0.05 . Therefore, the distribution of data follows non-normal distribution.

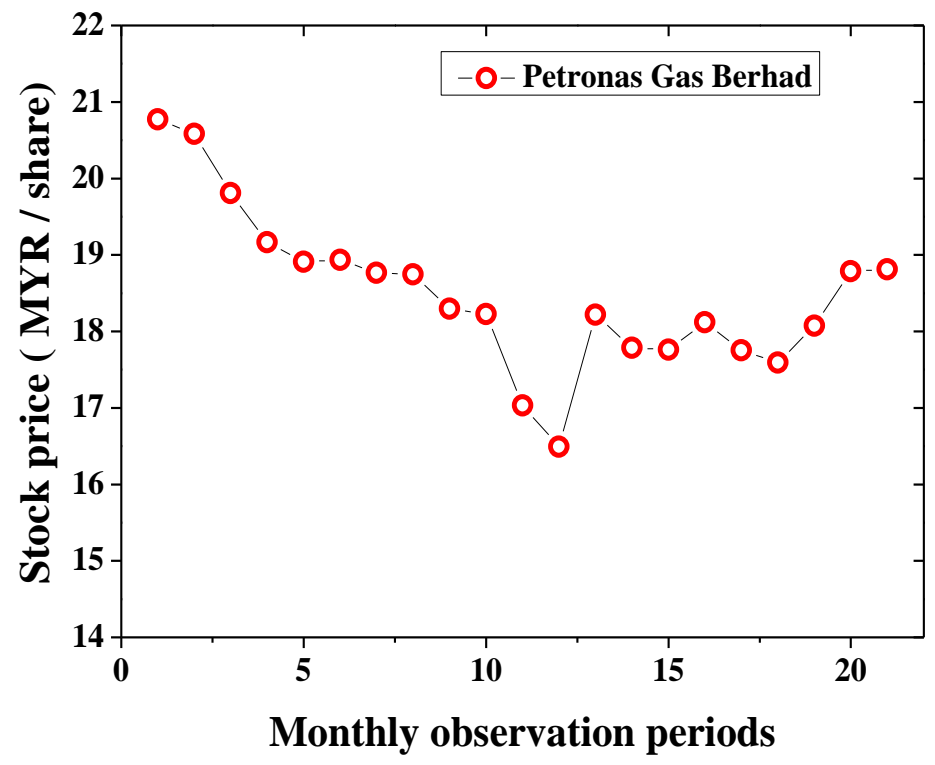

Figure 4:-Dynamic behavior of stock price for Petronas Gas Berhad

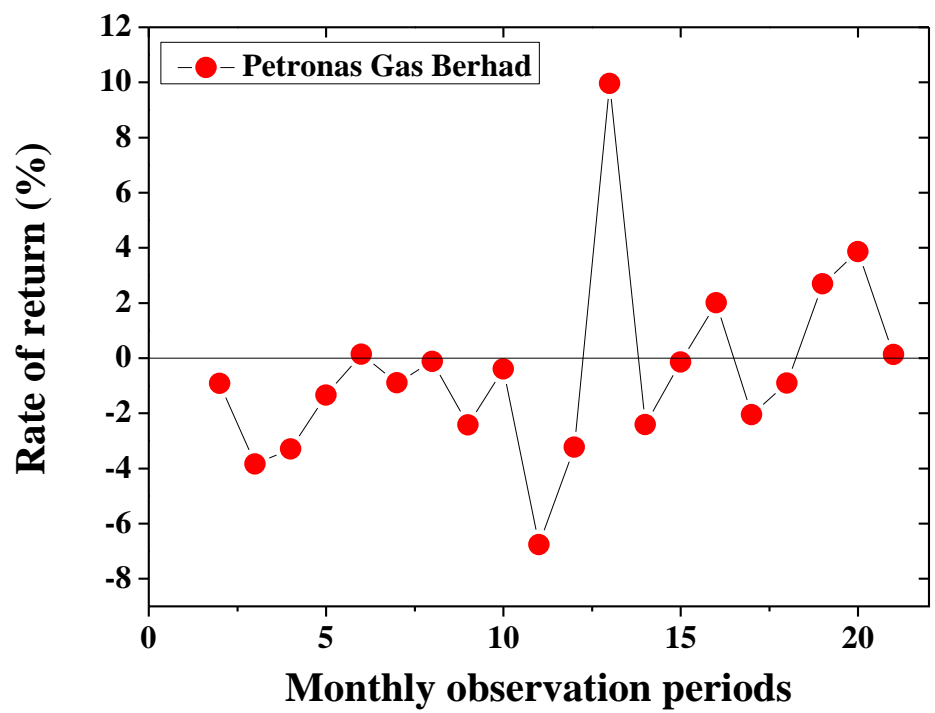

Figure 5:-Return rate of stock price for Petronas Gas Berhad 


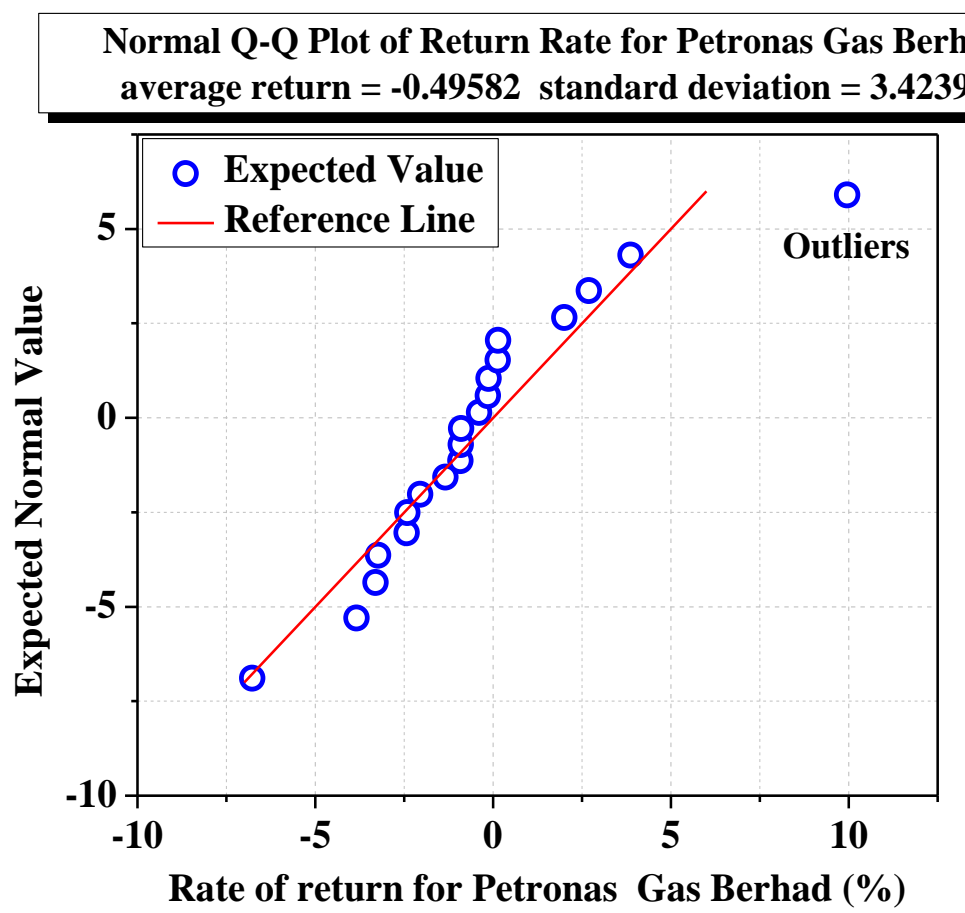

Figure 6:-Normal Q-Q normal plot of Return rate for stock price

Table 2:-Shapiro-Wilk normality test for stock price

\begin{tabular}{|c|c|c|c|}
\hline Test & \multicolumn{3}{|c|}{ Shapiro-Wilk normality test } \\
\hline Parameter & Statistics & Degrees of freedom $(\mathrm{df})$ & Significant value \\
\hline $\begin{array}{c}\text { Return Rate for stock price } \\
\text { (Petronas Gas Berhad) }\end{array}$ & 0.892 & 20 & 0.030 \\
\hline
\end{tabular}

\section{Correlation analysis for return rate}

Next, this study performed correlation analysis between Bitcoin return and stock return. Figure 7 shows correlation plot between Bitcoin return and stock return. The numerical analysis is carried out using linear regression line and Pearson correlation analysis.

The linear regression analysis is represented by Equation (11).

$$
y=m x+c
$$

Stock return $=-0.05($ Bitcoin return $)+0.01$

Equation (11) concludes for every increment in Bitcoin return, it is contributes to decrement of 0.05 to stock return namely Petronas Gas Berhad.

Next, this study performed analysis of Pearson product-moment correlation. Table 3 exhibits Pearson correlation analysis for association between return rate of Bitcoin and return rate of stock (Petronas Gas Berhad). The value of association is -0.372 . This value indicates there is negative and weak association between Bitcoin return and stock return. Next, the significant value of 2 -tailed statistics is 0.106 . This value is larger than 0.05 that indicates this study failed to reject null hypothesis. Therefore, this concluded there is insignificant and negative weak association between Bitcoin and stock return (Petronas Gas Berhad). 


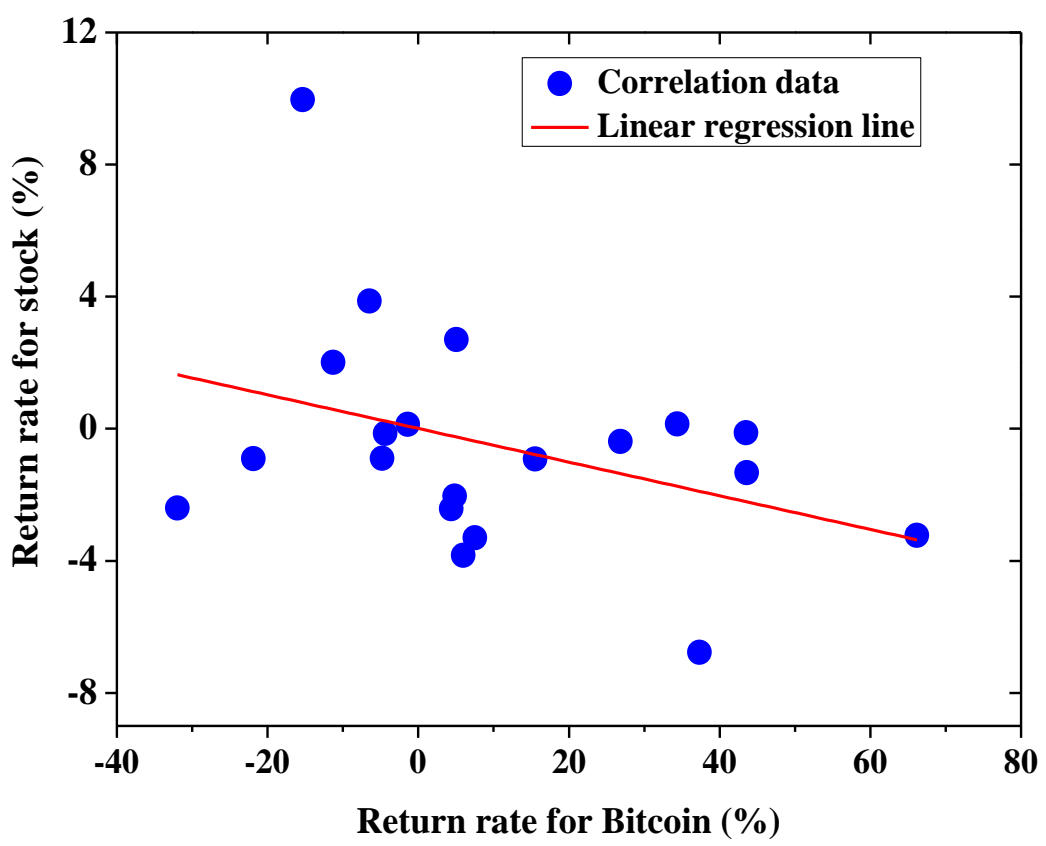

Figure 7:-Correlation plot between Bitcoin return and stock return

Table 3:-Pearson correlation analysis

\begin{tabular}{|c|c|c|}
\hline Pearson correlation coefficient & Number of pair for data & Significant value (2 tailed) \\
\hline-0.372 & 20 & 0.106 \\
\hline
\end{tabular}

Evaluation of portfolio expected return with portfolio risk using Modern Portfolio Theory

This section describes the portfolio risk and portfolio expected return for combination of Bitcoin and stock price (Petronas Gas Berhad). Figure 8 shows the relationship plot between portfolio risk and expected return for two asset combination of portfolio investment.

The diversification of investment in modern portfolio theory can lead to lower risk of portfolio. Therefore, this study tries to prove it using a calculation from combination of two assets that consists of cryptocurrency (Bitcoin) and stock price (Petronas Gas Berhad). The calculation is started with $0 \%$ of weightage in Bitcoin and $100 \%$ weightage in stock. Then, this study gradually decreases the weightage in stock and increase the weightage in Bitcoin.

Figure 8 indicates Bitcoin is a dominant in determining the expected return for portfolio investment. In this analysis mean return for Bitcoin is $9.890 \%$. Meanwhile, the mean return for stock price of Petronas Gas Berhad is -0.496 .

The combination two assets can reduce risk of the portfolio investment. This is proved by analysis that the portfolio risk with only Bitcoin composition is $24 \%$, and with the combination with stock price (Petronas Gas Berhad), the risk is reduced.

Finally, this study developed efficient frontier for portfolio investment. Figure 9 shows the efficient frontier for portfolio with combination of two assets. The efficient frontier is the set of optimal portfolios that offers the highest expected return for a defined level of risk or the lowest risk for a given level of expected return. Portfolios that lie below the efficient frontier are sub-optimal because they do not provide enough return for the level of risk. The right end of the efficient frontier includes assets combinations that are expected to have a high degree of risk coupled with high potential returns, which is suitable for highly risk-tolerant investors. In opposite, assets that lie on the left end of the efficient frontier would be suitable for risk-averse investors. 


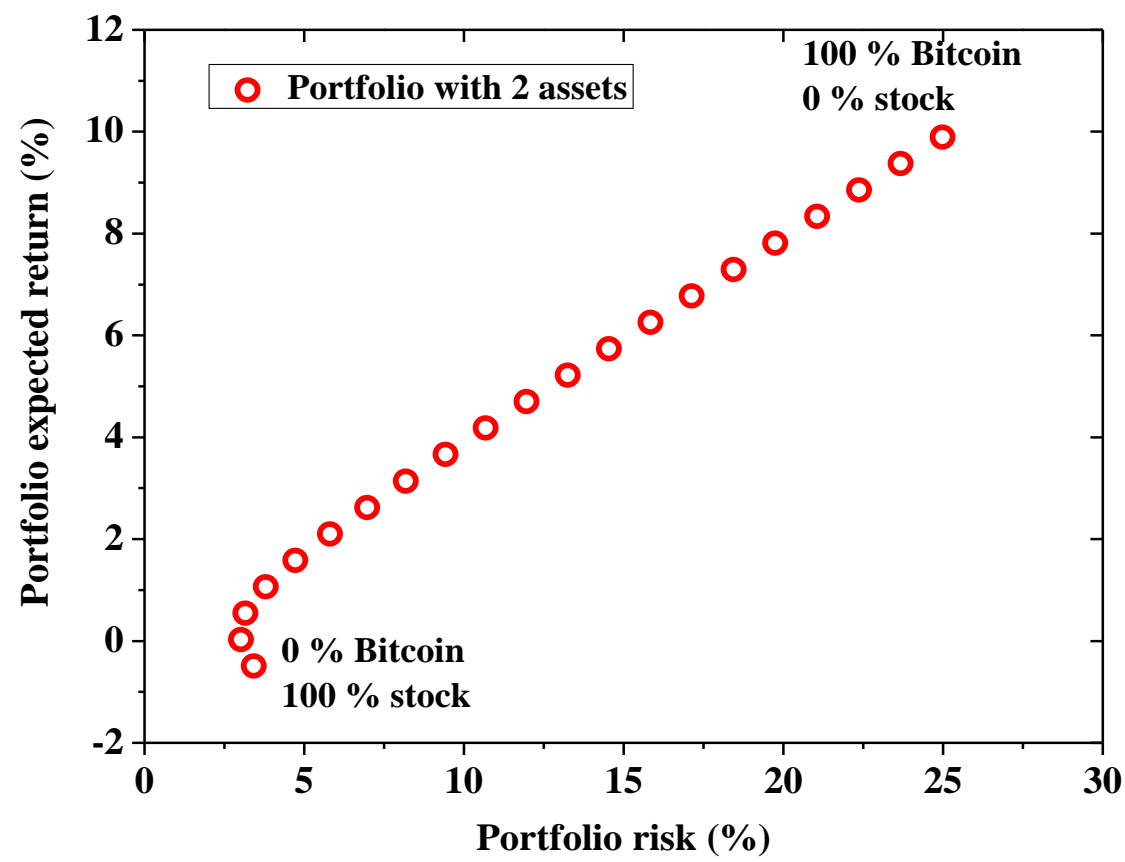

Figure 8:-Relationship plot between portfolio risk and expected return

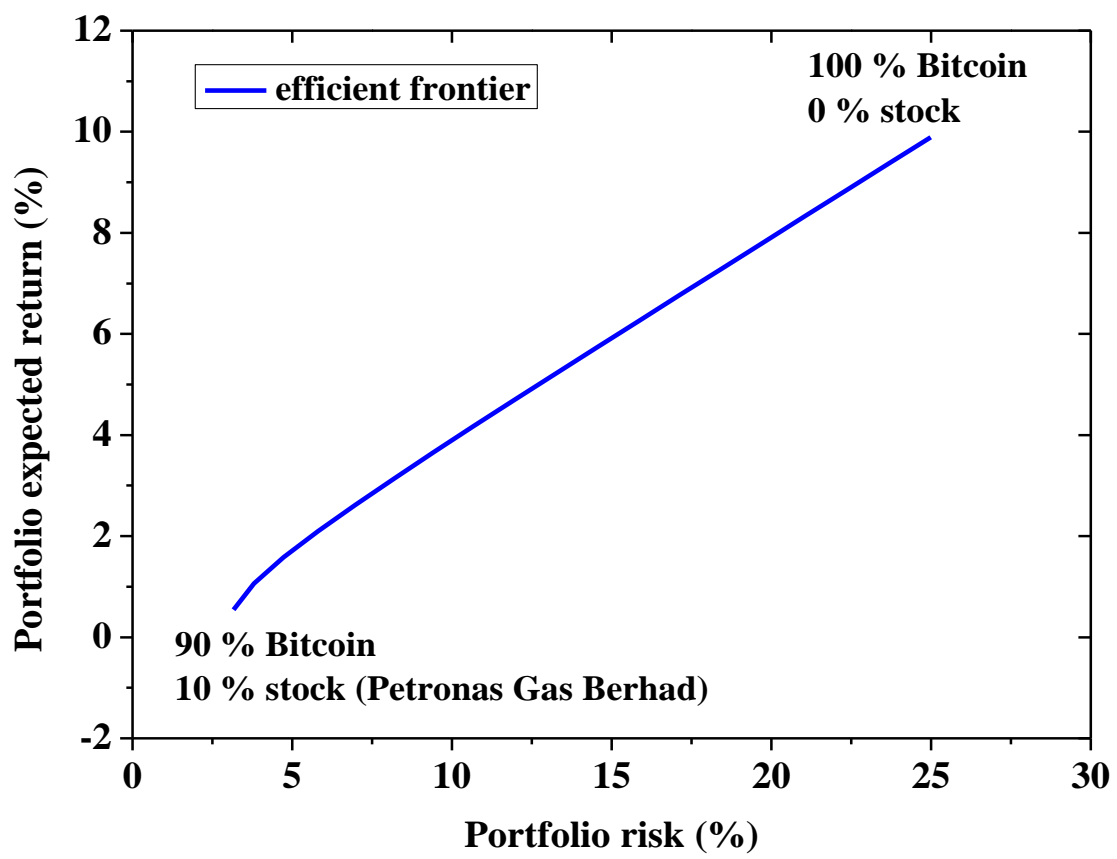

Figure 9:-Efficient frontier for portfolio investment

\section{Conclusion:-}

The main objective of this study is to develop optimal investment portfolio in reducing investment risk. This study combined two selected assets which are cryptocurrency (Bitcoin) and stock price (Petronas Gas Berhad). The main findings of this analysis are:

1. In this analysis mean return for Bitcoin is $9.890 \%$. Meanwhile, the mean return for stock price of Petronas Gas Berhad is $-0.496 \%$.

2. Pearson correlation analysis for association between return rate of Bitcoin and return rate of stock (Petronas Gas Berhad). The value of association is -0.372 . This value indicates there is negative and weak association between 
Bitcoin return and stock return. Next, the significant value of 2-tailed statistics is 0.106 . This value is larger than 0.05 that indicates this study failed to reject null hypothesis. Therefore, this concluded there is insignificant and negative weak association between Bitcoin and stock return (Petronas Gas Berhad).

3. The combination two assets can reduce risk of the portfolio investment. This is proved by analysis that the portfolio risk is $24 \%$ when the investment portfolio is develop by only Bitcoin composition. Meanwhile, the investment risk is reduced for portfolio combination of Bitcoin with stock price (Petronas Gas Berhad).

4. The efficient frontier is the set of optimal portfolios that offers the highest expected return for a defined level of risk or the lowest risk for a given level of expected return. Portfolios that lie below the efficient frontier are suboptimal because they do not provide enough return for the level of risk. The right end of the efficient frontier includes assets combinations that are expected to have a high degree of risk coupled with high potential returns, which is suitable for highly risk-tolerant investors. In opposite, assets that lie on the left end of the efficient frontier would be suitable for risk-averse investors.

\section{Implications of study:-}

The findings of this study will help investors to select appropriate assets for their investment portfolio. In the same time, the investor can access and evaluate their expected return and investment risk.

\section{Further study:-}

This study can be extending to evaluate the factors for dynamic behavior of price in each of the asset. In addition, the forecasting of share price for each asset also is interesting area for discover in the future.

\section{References:-}

1. Abu Bakar, N. and Rosbi, S. (2016) Reliability of Exponential Smoothing Method for forecasting Islamic Share Price to oil and gas sector in Malaysian Stock Exchange, International Academic Research Journal of Business and Technology, Vol. 2, No. 2, pp. 38-44

2. Abu Bakar, N. and Rosbi, S. (2017) Statistical non-parametric correlation diagnostic for dynamic behavior of Malaysian currency with world crude oil price, International Journal of Economics, Commerce and Management, Vol. V, Issue 5, pp. 1-13

3. Abu Bakar, N., Rosbi, S. and Uzaki, K. (2017) Cryptocurrency Framework Diagnostics from Islamic Finance Perspective: A New Insight of Bitcoin System Transaction, International Journal of Management Science and Business Administration, Vol. 4, Issue 1, pp. 19-28

4. Abu Bakar, N. and Rosbi, S. (2017) Identification of non-equilibrium growth for Bitcoin Exchange rate: Mathematical derivation method in Islamic Financial Engineering, International Journal of Scientific Research and Management, Vol. 5, No. 12, pp. 7772-7781

5. Abu Bakar, N. and Rosbi, S. (2018) Robust Framework Diagnostics of Blockchain for Bitcoin Transaction System: A Technical Analysis from Islamic Financial Technology (i-FinTech) Perspective, International Journal of Business and Management, Vol. 2, No.3, pp. 22-29

6. Abu Bakar, N. and Rosbi, S. (2018) Efficient frontier analysis for portfolio investment in Malaysia stock market, Science International, Vol. 30, No. 5, pp. 723-729

7. Azizan, N.A. and Sorooshian, S. (2014) Stock Market performance and modern portfolio theory: Case on Malaysian stock market and Asian Indices, WSEAS Transactions on Business and Economics, Vol. 11, pp. 303313

8. Basilio, M.P., Freitas, J.G., Kämpffe, M.G.F. and Rego, R.B. (2018) Investment portfolio formation via multicriteria decision aid: a Brazilian stock market study, Journal of Modelling in Management, Vol. 13, No. 2, pp.394-417

9. Bajpai, P. (2018) Bitcoin Vs Ethereum: Driven by Different Purposes, available at: https://www.investopedia.com/articles/investing/031416/bitcoin-vs-ethereum-drivendifferent-

purposes.asp\#ixzz5BODKZUe4 (accessed 10 April 2018)

10. Draper, D. W. and Findlay, M. C. (1982) Capital Asset Pricing and Real Estate Valuation, Journal of the American Real Estate and Urban Economics Association, Vol. 10, pp. 152-183

11. Decker, C. and Wattenhofer, R. (2013) Information propagation in the Bitcoin network, IEEE P2P 2013 Proceedings, Trento, pp. 1-10

12. Eldomiaty, T., Lotfy, I.S., Rashwan, M. and El Din, M.B. (2016) Robustness of firm-specific and macroeconomic determinants of exploration investments: Implications from Egyptian oil \&gas industry, Journal of Economic and Administrative Sciences, Vol. 32, No. 2, pp. 137-159 
13. Fabozzi, F.J., Gupta, F. and Markowitz, H.M. (2002) The Legacy of Modern Portfolio Theory,The Journal of Investing, pp. 7-22

14. Friedman, H. (1971) Real Estate Investment and Portfolio Theory, Journal of Financial and Quantitative Analysis, Vol. 6, No. 2, pp. 861-874

15. Garcia, R., Lessard, D. and Singh, A. (2014) Strategic partnering in oil and gas: A capabilities perspective, Energy Strategy Reviews, Vol. 3, pp. 21-29

16. Giannotti, C., Mattarocci, G. and Spinelli, L. (2011) The role of portfolio diversification in the hotel industry: Evidence from the Italian market, EuroMed Journal of Business, Vol. 6, No. 1, pp. 24-45

17. Hin/David Ho, K., Hui, E.C.M. and Su, H. (2010) Examining fuzzy tactical asset allocation (FTAA) as an alternative to modern portfolio theory (MPT) asset allocation for international and direct real estate investment, Journal of Financial Management of Property and Construction, Vol. 15, No. 1, pp. 71-94

18. Kristoufek, L. (2013) BitCoin meets Google Trends and Wikipedia: Quantifying the relationship between phenomena of the Internet era. Scientific reports

19. Moore, T. and Christin, N. (2013). Beware the middleman: Empirical analysis of Bitcoinexchange risk. International Conference on Financial Cryptography and Data Security, Springer, Berlin, Heidelberg, pp. 2533

20. Mohd Ali, H. (2006) Modern Portfolio Theory: Is There Any Opportunity for Real Estate Portfolio?,Malaysian Journal of Real Estate, Vol. 1, No. 1, pp. 14-26

21. Markowitz, H, (1952) Portfolio Selection,Journal of Finance, Vol. 7, No.1, pp. 77-91

22. Nakamoto, S., (2009) Bitcoin: A Peer-to-Peer Electronic Cash System, available at: http://bitcoin.org/bitcoin.pdf (accessed 20 October 2017)

23. Ou, J. (2005) Theory of portfolio and risk based on incremental entropy,The Journal of Risk Finance, Vol. 6, No. 1, pp. 31-39

24. Reynolds, P. and Irwin, A.S.M. (2017) Tracking digital footprints: anonymity within the bitcoin system, Journal of Money Laundering Control, Vol. 20, No. 2, pp.172-189

25. Simser, J. (2015) Bitcoin and modern alchemy: in code we trust, Journal of Financial Crime, Vol. 22, No. 2, pp.156-169. 